\title{
Isolated Intracranial Rosai-Dorfman Disease Mimicking a Meningioma
}

\author{
Amer Alshurbaji MD ${ }^{1}$, Alhareth Ma'aya MD ${ }^{1 *}$, Faisal Alshurbaji MD ${ }^{1}$, Wagdy Al-Kadasi MD ${ }^{1}$ and Duaa \\ Alshurbaji MD²
}

${ }^{1}$ Department of Neurosurgery, King Hussein Medical Center, Jordan

${ }^{2}$ Department of Histopathology, King Hussein Medical Center, Jordan

Submission: April 04, 2017; Published: July 31, 2017

*Corresponding author: Alhareth Ma'aya MD, Department of Neurosurgery, King Hussein Medical Center, Amman, Jordan, Email: alhareth1947@gmail.com

\begin{abstract}
Rosai-Dorfman disease (RDD) is a rare idiopathic his to proliferative disorder that usually presents with systemic symptoms and cervical lymphadenopathy. Intracranial involvement is relatively rare and isolated intracranial RDD is very scarce. It resembles meningioma on imaging scans and is difficult to differentiate preoperatively. We present our case of isolated intracranial RDD in 25 years-old man that mimicked a meningioma on imaging.
\end{abstract}

Keywords: Rosai-dorfman disease; Sinus histocytosis; Meningioma

\section{Introduction}

Rosai-Dorfman disease; described as benign lymphohistiocytosis, typically involves lymph nodes and usually presents as massive lymphadenopathy with sinus histocytiosis. Clinically it presents as painless cervical lymphadenopathy with fever, on laboratory testing; there is leukocytosis, elevated ESR and polyclonal hypergammaglobulinemia. The first report of the disease was by Destombes in 1965, in 1969 it was described by Juan Rosai and Roland Dorfman, as sinus histocytosis with massive lymphadenopathy in young black males. The disease mainly affects children and young adults with a mean age of presentation of 20.6 years but can be seen in any of those between 1 to 74 years old. There is a slight male predominance (male: female $=1.4: 1$ ) [1]. The involvement of the central nervous system has been reported in less than 5\%. Extra nodal involvement (reported in more than $90 \%$ of patients) presents with cervical lymphadenopathy, and in $43 \%$ of cases it included the par nasal sinuses, skin, bone, and orbit [2].

\section{The Case}

A 25-year-old man presented to the emergency department with a generalized tonic-clonic seizure, he had no history of prior illness. Neurological examination was unremarkable and there were no focal deficits. A computerized tomography CT of the head revealed a well-circumscribed extra-axial mass in the left tentorial region. Magnetic resonance imaging (MRI) further revealed the left extra-axial tentorial lesion to be attached to the transverse sinus and causing mild mass effect with severe perilesional edema. The lesion appeared hypointense on T1WI and hypointense on T2WI. Contrast enhanced images showed homogeneous enhancement of the lesion with adherence to the dura of the convexity and transverse sinus (Figure 1).

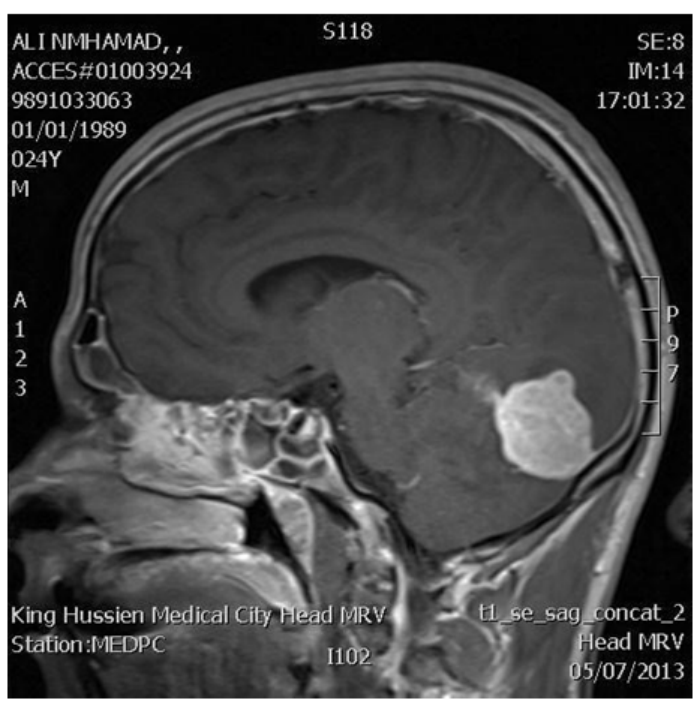

Figure 1: T1-contrasted sagittal MRI showing homogenous enhancement of the tentrorial lesion. 


\section{Open Access Journal of Neurology \& Neurosurgery}

Meningioma was considered the most likely diagnosis Routine hematological and biochemical studies were normal. The patient underwent a left occipital craniotomy with complete excision of the lesion which was firm, grayish-yellow in color and measured $5 \mathrm{~cm}$ in diameter, it was insignificantly vascular. The postoperative course was uneventful. Post-operative MRI is shown in Figure 2. Microscopically examination of the lesion revealed a mixed lymphoplasmacytic inflammatory infiltrate containing sheets of large and foamy histiocytes. Some of these histiocytes engulfed many lymphocytes and plasma cells, corresponding to emperipolesis (Figure 3).

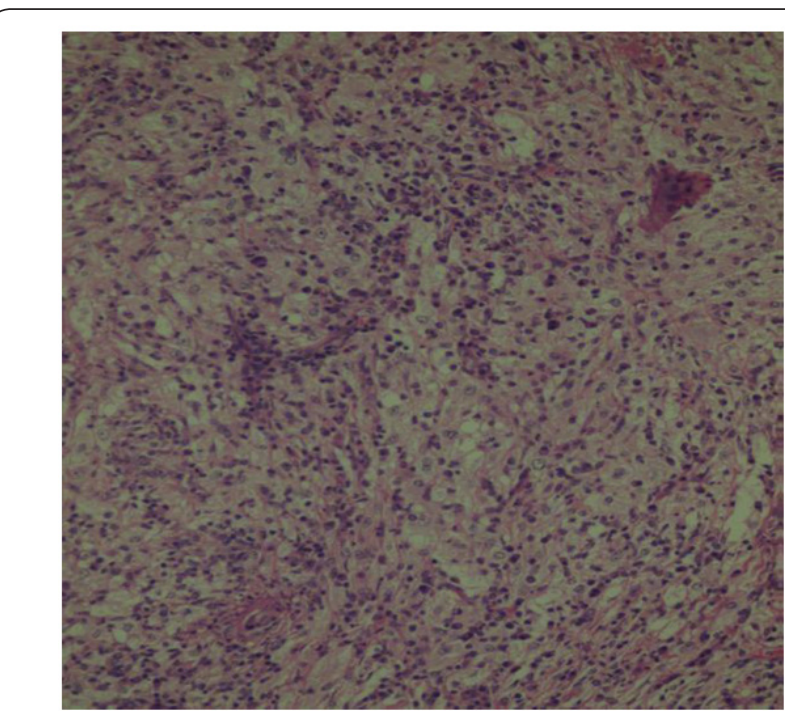

Figure 2: Histiocytes engulfing several small lymphocytes (emperipolesis) HE.

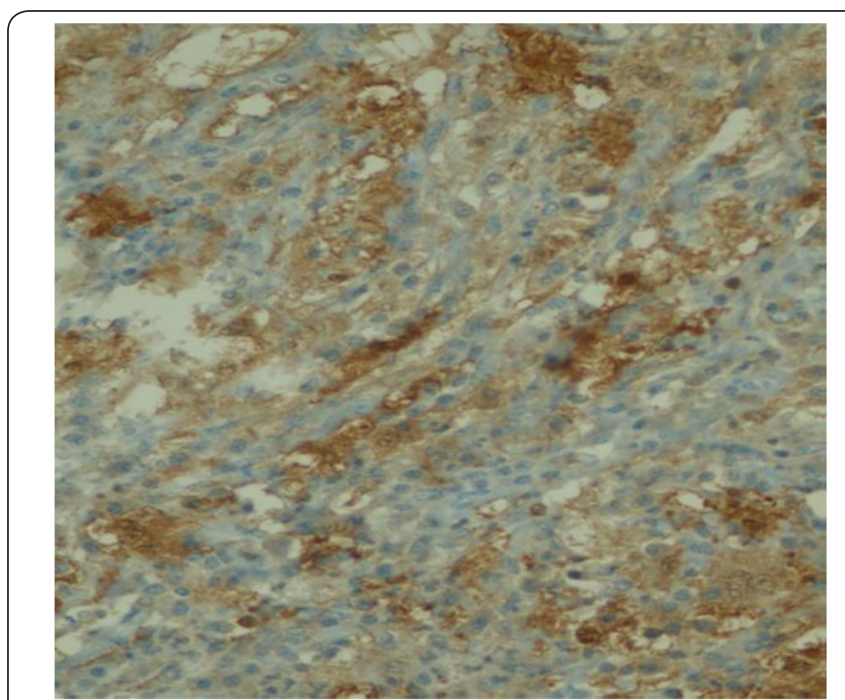

Figure 3: the large histiocytic cells are positive for $\mathrm{S} 100$.

Figure 2 by immune histochemistry, histiocytic cells were positive for S100 protein (Figure 4), as well as for CD68 (Figure 5). In the 3 year, postoperative follow-up of the patient; no recurrence was noted, no lymphadenopathy or systemic masses were identified on admission and on follow up. The case was discussed with the oncology team and no adjuvant treatment was administrated.

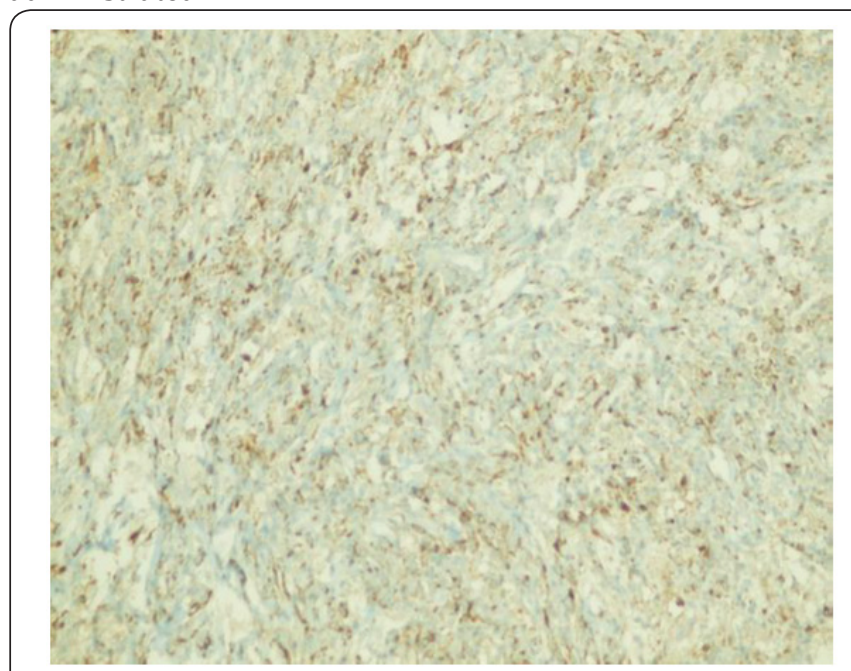

Figure 4: The large histiocytic cells are positive for CD 68.

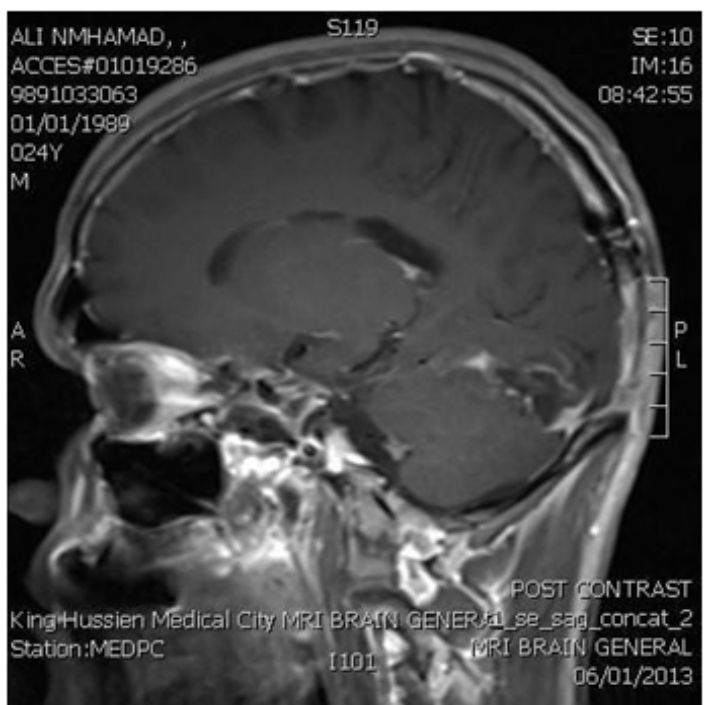

Figure 5: post-operative T1 contrasted sagittal MRI.

\section{Discussion}

RDD is also known as a sinus histocytosis with massive lymphadenopathy. Nevertheless, the use of this term in the central nervous system is not well suited because of the absence of lymphadenopathy in the vast majority of cases. Involvement of the CNS is much less frequent, occurring in $<5 \%$ of RDD patients.

The age distribution at the time of onset of the disease ranged from less than 1 year to 74 years. The CNS-RDD shows a predilection for men and usually presents during the fourth to fifth decade [3]. The mean age at presentation is 41 years. Deodhare et al noticed that the age of onset in patients with intracranial localization of RDD differs from those with nodal-based RDD (37.5 yr versus $20.6 \mathrm{yr}$ ). The common sites of RDD in the CNS are the cerebral convexity, cranial base, parasagittal, suprasellar 
region, cavernous sinus, and petroclival region; intraparenchymal and intraventricular lesions could be also found. Clinically, like meningiomas, intracranial RDD causes a variety of symptoms depending on lesion location. Thus headache, epilepsy, visual and hearing loss, cranial nerve deficits, weakness of limbs, confusion, short-term memory problems, difficulty with speech, visual hallucinations and various other symptoms may be seen or become evident with disease progression.

Radio logically; intracranial RDD mimic meningiomas Kumar et al. [2]. Compared plain x-ray film radiography in the cases of meningioma with RDD, he found that hyperostosis, erosion, calcification of tumor and enlarged vascular channels are not present in RDD. Perilesional edema is less prominent in case of RDD as compared to meningioma [2]. The characteristic microscopic features of RDD are infiltration of histiocytes, B and $\mathrm{T}$ lymphocytes and plasma cells. Emperipolesis is typical of $\mathrm{RDD}$ of the leptomeninges but is not seen in $30 \%$ of cases [4] On immunocytochemical studies, expression of CD68, CD31, a1 antitrypsin and a1 antichymotrypsin are positive both for mononuclear cells and dendritic cells, but a positive expression of S100 is found only for dendritic cells. CD1a is not expressed by any cells in RDD.As it is explained by Puravin's recent series (which included 10 cases ofRDD) the centralnervous system RDD diagnosis was based entirely on histopathology and immunohistochemistry [5]. The differential diagnosis may include other pathologies characterized by dural involvement and strong enhancement after gadolinium injection, as such as meningioangiomatosis, dural metastases, Wegener's granulomatosis, ErdheimChester disease, sarcoidosis, Hodgkin lymphoma, plasma cell granuloma, inflammatory pseudo tumor and Langerhans histocytosis. Most of the patients with intracranial lesions were treated surgically. At surgery, Rosai-Dorfman disease lesions in the central nervous system are firm, lobular, whitish gray or yellowish tan in color and adherent to the dura. The diagnosis can only be confirmed by histopathological/ immunohistochemical examination of the tissues. Intraoperative pathological diagnosis can be misleading [6]. Surgeries were performed in $93 \%$ with preoperative diagnosis being meningioma. Resection of intracranial mass is the most effective treatment for intracranial RDD [7]. Adjuvant treatment includes steroids, irradiation, and chemotherapy. McPherson et al reported regression of intracranial RDD following corticosteroid therapy Hadjipanayis et al. [8]. reported a case of intracranial Rosai-Dorfman disease treated with microsurgical resection and stereotactic radio surgery with significant regression Horneff et al. [9]. Reported a good response of RDD to methotrexate and mercaptopurine. Aouba et al. noted a patient with systemic
RDD was asymptomatic after 3 cycles of cladribine treatment. Petyold et al. reported that $14 \%$ intracranial tumor regrowth or recurrence of symptoms and he advised to ensure 5 years follow up period (median relapse time) and recommend post-operative local low dose radiation with subtotal tumor resection or recurrence of symptoms [10]. The etiology of RDD is still obscure, the immunophenotypic profile and studies of onokine expression suggest derivation from activated macrophages that produce interleukin-1b (IL 1-b) and tumor necrosis factor-a (TNF-a). Levine et al. reported detection of human herpes virus in tissues involved by sinus histocytosis with massive lymphadenopathy (Rosai Dorfman disease).

\section{Conclusion}

RDD mimicking a meningioma is a very rare and it can't be diagnosed preoperatively unless there is a suspension of systemic manifestations. Radiology findings are identical to those of meningioma. Total resection if safe can achieve cure of the intracranial disease. Follow up for 5 years is recommended by most authors to detect early relapse.

\section{References}

1. Huang YT, Ng SH, Ko SF (2009) Extranodal Rosai Dorfman disease with paranasal sinuses and intracranial involvement: a case report. Chinese Journal of Radiology 34(3): 191-196.

2. Kumar R, Singhal U, Mahapatra AK (2011) Intracranial Rosai- Dorfman syndrome. Pan Arab Journal of Neurosurgery 15(1): 58-63.

3. Said R, Abi-Fadel F, Talwar J, Attallah JP, Dilawari A (2011) Intracranial Rosai-Dorfman: A clinical challenge. Neurologist 17: 117-119.

4. Castellano-Sanchez AA, Brat DJ (2003) May 2003: 57-yearoldwoman with acute loss of strength in her right upper extremity and slurred speech. Brain Pathol 13(4): 641-642,645.

5. Purav P, Ganapathy K, Mallikarjuna VS (2005) Rosai-Dorfman disease of the central nervous system. J Clin Neurosci 12: 656-659.

6. Adeleye A, Amir G, Fraifeld S, Shoshan Y, Umansky F, Spektor S (2010) Diagnosis and management of Rosai-Dorfman disease involving the central nervous system. Neurol Res 32(6): 572-578.

7. Griffiths SJ, Tang W, Parameswaran R, Kelsey A, West CG (2004) Isolated intracranial Rosai-Dorfman disease mimicking meningioma in a child. Br J Neurosurg 18(3): 293-297.

8. McPherson CM, Brown J, Kim AW, DeMonte F (2006) Regression of intracranial rosai-dorfman disease following corticosteroid therapy. Case report. J Neurosurg 104(5): 840-844.

9. Hadjipanayis CG, Bejjani G, Wiley C, Hasegawa T, Maddock M, et al. (2003) Intracranial RosaiDorfman disease treated with microsurgical resection and stereotactic radiosurgery. Case report. J Neurosurg 98(1): 165-168.

10. Petzold A, Thom M, Powell M, Plant GT (2001) Relapsing intracranial Kosai Dorfman disease. J NeurolNeurosurg Psychiatry 71(4): 538-541. 


\section{Your next submission with Juniper Publishers will reach you the below assets}

- Quality Editorial service

- Swift Peer Review

- Reprints availability

- E-prints Service

- Manuscript Podcast for convenient understanding

- Global attainment for your research

- Manuscript accessibility in different formats

( Pdf, E-pub, Full Text, Audio)

- Unceasing customer service

Track the below URL for one-step submission https://juniperpublishers.com/online-submission.php 